\title{
RESEARCH ON TRIBOLOGICAL PROPERTIES OF DENTAL COMPOSITE MATERIALS
}

\author{
Krzysztof Dziedzic', Joanna Zubrzycka-Wróbel², Jerzy Józwik³, \\ Marcin Barszcz' ${ }^{1}$ Piotr Siwak ${ }^{4}$, Renata Chałas ${ }^{2}$
}

1 Department of Fundamental of Technology, Fundamentals of Technology Faculty, Lublin University of Technology, ul. Nadbystrzycka 38, 20-618 Lublin, Poland, e-mail: k.dziedzic@pollub.pl

2 Department of Conservative Dentistry and Endodontics, Medical University of Lublin, ul. Karmelica 7, 20-081 Lublin, Poland

3 Department of Production Engineering, Mechanical Engineering Faculty, Lublin University of Technology, ul. Nadbystrzycka 38, 20-618 Lublin, Poland

4 Faculty of Mechanical Engineering and Management, Institute of Mechanical Technology, Poznań University of Technology, ul. Piotrowo 3, 60-965 Poznań, Poland

Received: 2016.08.02

Accepted: 2016.10.08

Published: 2016.12.01

\begin{abstract}
Dental practice today used a lot of different materials. This paper evaluates tribological and mechanical properties of two dental materials CeramX and I-Light. Tribological analysisad of samples was conducted at temperature $37^{\circ} \mathrm{C}$ and in the environment of artificial saliva. The wear rate was evaluated with a ball-on-disc tribotester, in accordance to ASTM G-133 norm. The counterbodies were 6-mm-in-diameter $\mathrm{Al}_{2} \mathrm{O}_{3}$ steel balls. The load of 2, 10 and $20 \mathrm{~N}$ was applied. The tests were conducted at 0.15 $\mathrm{m} / \mathrm{s}$ sliding velocity over a sliding stroke of $1000 \mathrm{~m}$. The changes in the value of the following parameters were measured during the trials: friction coefficient, friction force, temperature and wear depth. After completing the tribological tests the surface of samples was carried out.
\end{abstract}

Keywords: dental materials, biotribology, friction coefficient, wear.

\section{INTRODUCTION}

One of the areas of tribology dealing with the description of friction, wear and lubrication of the friction nodes of living organisms is biotribology. Tribological processes in living organisms occur in friction nodes, such as: joints, stomatgnathic system (temporomandibular joint, periodontal joint and dental joint), etc. [1, 2]. One of the basic problems associated with friction nodes in living organisms is determination of their durability and stability. Biomaterial is any substance other than a drug or combination of synthetic or natural substances, whose task is to supplement or replace the tissues of an organ or its part in order to meet their specific functions [3].
The materials used as dental fillings should be characterized by good adhesion to the enamel and dentin, and resistance to impact and fatigue, wear resistance through friction and low polymerization shrinkage to prevent the formation of microcracks and bacterial leakage. In addition, they should be characterized by high biotolerance and aesthetic qualities (natural appearance of the tooth) $[4,5]$.

Manufacturers of dental materials offer ever new materials for fillings. The main group of materials that rebuild hard tissue are composite materials. They combine good performance and aesthetic properties. The mechanical properties of the composites depend largely on the type, particle size of the filler and its quantity. The wear of 
dental materials is one of the main disadvantages of fillings. Wear and its character is influenced by the amount and type of consumed food and drinks, composition and presence of saliva, oral hygiene and the use of additional hygiene measures, such as the type of toothpaste and toothbrushes, abnormalities and malocclusion. Since 1961, when Bowen introduced composite materials, they have been continuously updated and modified [6]. The main directions of changes include the reduction of particle size in the filler and increase of its amount, increase of the amount of released $\mathrm{F}$ ions having a prophylactic effect and increase of the aesthetic appeal [7-9].

The evaluation of tribological properties and dental materials is carried out on tribotesters and specially constructed devices that are designed to replicate conditions in the mouth and friction of tooth-tooth $[10,11]$.

\section{MATERIALS AND METHODS}

The objects of the study were dental composite materials CeramX mono and I-Light. CeramX mono is a nano-hybrid material used for the rebuilding of all cavity classes according to Black. According to the manufacturer, CeramX provides excellent functional properties and ease of modeling. I-Light is a nano-hybrid composite material used for rebuilding of all cavity classes according to Black. According to the manufacturer, it is characterized by exceptional durability and aesthetic values. In addition, several advantages of the I-Light material are homogeneity, polishability and color fastness.

Tribological tests were conducted on tribotester THT 1000 Anton Parr (Fig. 1a). Studies were carried out according to ASTM G133 and a friction of the ball-on-disc type. Samples of the composites were made in the shape of a disc with dimensions $\varnothing 29,5 \mathrm{~mm} \times 8 \mathrm{~mm}$. The material was applied in layers $(2 \mathrm{~mm})$ into the matrix and then irradiated with a halogen lamp. After completing the polymerization process, researchers began to polish the samples using sanding discs of different grain, rubber bands and polishing pastes. The applied counterspecimen materials were balls with a diameter of $6 \mathrm{~mm}$, made of $\mathrm{Al}_{2} \mathrm{O}_{3}$. A load of $2 \mathrm{~N}, 10 \mathrm{~N}$ and $20 \mathrm{~N}$ was applied during tribological tests. The research was conducted on a sliding friction node at the speed of $0.15 \mathrm{~m} / \mathrm{s}$ at a radius of $3 \mathrm{~mm}$. The total distance of friction

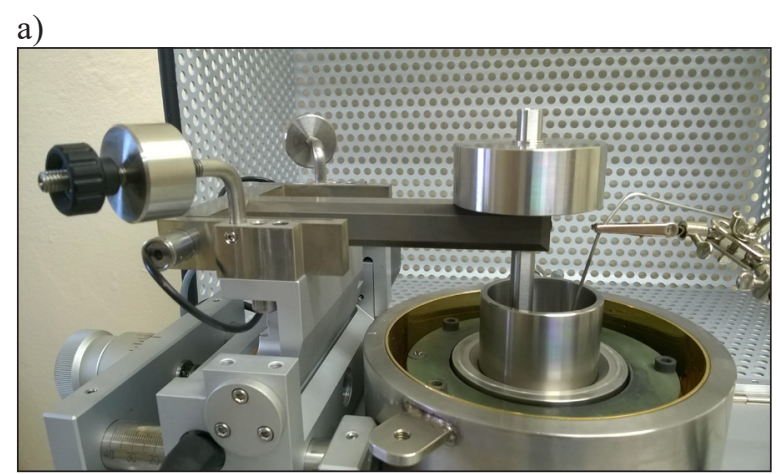

b)

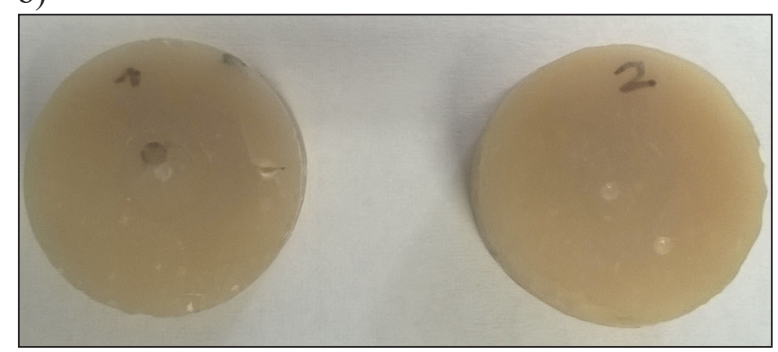

Fig. 1. Workstation for tribological tests - tribotester THT 1000 (a) and the view of samples used for testing (b)

was $1000 \mathrm{~m}$. Due to the fact that dental composites are used as a material for dental cavities, the tribological tests were performed at $37^{\circ} \mathrm{C}$ and in the environment of artificial saliva. The volume of artificial saliva in the container in each test was $5 \mathrm{ml}$. During tribological tests the sample surface was covered with artificial saliva in thicknesses of up to $2 \mathrm{~mm}$. The temperature was measured via a thermocouple at $2 \mathrm{~mm}$ from the surface of friction. A change of the friction coefficient, friction force and temperature was recorded during the test. The frequency of data collection was $10 \mathrm{~Hz}$.

A comparative measure of wear, which takes into account the load and distance of friction, was a coefficient of wear calculated for a pair of friction, according to ASTM G133 using the following equation (1).

$$
w_{d}=\frac{V_{f}}{F_{n} \times l}
$$

where: $w_{d}$ - coefficient of wear,

$$
\begin{aligned}
& V_{f}-\text { wear volume, } \\
& F_{n}-\text { loading force, } \\
& l^{n} \text { - distance of friction. }
\end{aligned}
$$

The measure of wear in the sample was loss of volume, formed as a trace of wear resulting from cooperation with the counterspecimen material. For this purpose, a profile field was measured perpendicular to the tracks of samples using the 
Surtronic $3+$ profilometer on the circumference of the sample (in 10 locations). Measurements were made on the measurement section of $4 \mathrm{~mm}$. The wear volume was determined as the product of the mean value of the sample and circumference of the wheel track resulting from the ball-on-disc test, according to the following equation (2).

$$
V_{f}=A \times L
$$

where: $V_{f}$-wear volume,

$A$ - average cross-sectional area of the track,

$L$ - length of the stroke.

Wear of the counterspecimen material was calculated by measuring the diameters of wear using a metallographic microscope and equations (3) and (4).

$$
\begin{gathered}
V=\frac{\pi h^{2}}{3}(3 r-h) \\
h=r-\sqrt{r^{2}-\left(\frac{d}{2}\right)^{2}}
\end{gathered}
$$

where: $r$ - sphere radius,

$h$ - spherical cap height,

$d$ - spherical cap diameter (experimentally measured).

The wear surface was evaluated after the tribological tests. The surface of samples and counterspecimen materials were also tested before tribological tests in order to analyze the obtained results. The first stage involved tests of roughness parameters that were measured before and after tribological tests using the Surtronic $3+$ profilografometer (according to PN ISO 4288). The next stage involved microscopic examinations. Observations of the microstructure of samples were made at various magnifications using a metallographic microscope. The tests of microhardness used Nanointender Picodentor HM500 from Fischer. The applied load amounted to $300 \mathrm{mN}$.

\section{RESULTS AND DISCUSSION}

The aim of the study was to determine and compare the basic mechanical properties and tribological properties of two light-curing nano-hybrid composite materials named CeramX mono and I-Light, used to rebuild hard tissues of the tooth. These materials are typical representatives of this group of composites. The study showed that the roughness of front surfaces after sanding (before friction) was $\mathrm{R}_{\mathrm{a}}=0.57 \mu \mathrm{m}$ for the Ce$\operatorname{ramX}$ material and $\mathrm{R}_{\mathrm{a}}=0.68 \mu \mathrm{m}$ for the i-Ligt material. The measured average microhardness of the surface was $80.97 \mathrm{HV}$ for the CeramX material and $68.43 \mathrm{HV}$ for the I-Light material. The measured average Young's modulus of the samples was $14.73 \mathrm{GPa}$ for the CeramX material, and 14.69 GPa for the I-Light material.

The first stage of tribological studies involved tribological tests for the I-Light and CeramX materials with a load of $2 \mathrm{~N}$. In this case, there were no significant signs of wear for both samples and counterspecimen materials with $\mathrm{Al}_{2} \mathrm{O}_{3}$ after microscopic examinations. The wear volume has minimum values, which could not be quantified at low loads and in the presence of lubricant in the form of artificial saliva.

The next stage determined the wear volume for the samples after testing at a load of $10 \mathrm{~N}$ using the (2) equation. The wear volume for the I-Light material was $0.167 \mathrm{~mm}^{3}$, and slightly lower $-0,136 \mathrm{~mm}^{3}$ - for the CeramX material. The next stage involved evaluation of wear volume for samples after tests at a load of $20 \mathrm{~N}$. It amounted to $0.26 \mathrm{~mm}^{3}$ for the I-Light material, and $0.17 \mathrm{~mm}^{3}$ for the CeramX material. When analyzing the results of volumetric wear, it can be seen that wear of the CeramX samples is lower at a load of 10 and $20 \mathrm{~N}$. There were no signs of wear of the counterspecimen material from $\mathrm{Al}_{2} \mathrm{O}_{3}$, which is characterized by higher hardness. The tests showed wear of only one friction body (samples of materials). The maximum Hertzian stress during the test at a load of $10 \mathrm{~N}$

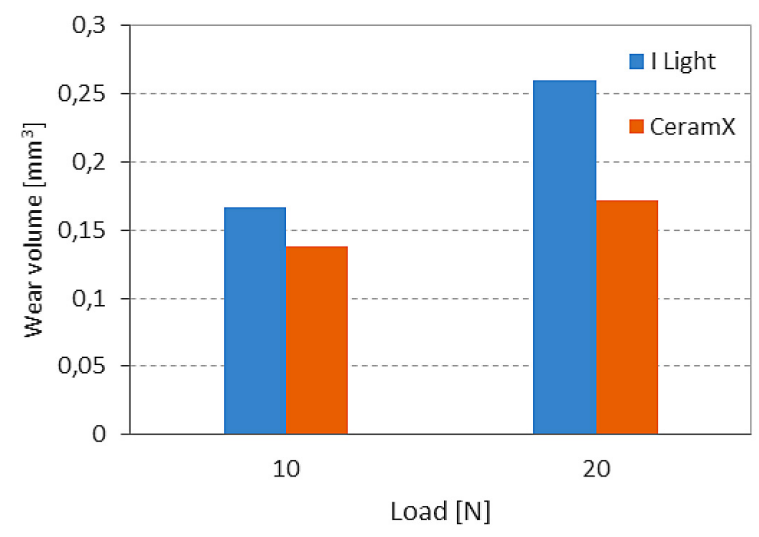

Fig. 2. Wear volume for the I-Light and CeramX materials 


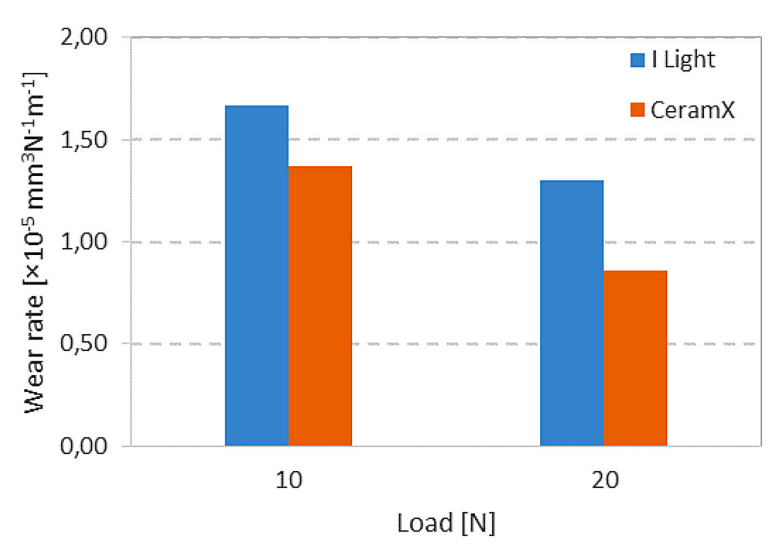

Fig. 3. The coefficient of wear for the I-Light and CeramX materials at loads of $10 \mathrm{~N}$ and $20 \mathrm{~N}$

amounted to $370 \mathrm{MPa}$, and $467 \mathrm{MPa}$ at a load of 20 N. Figure 2 shows the wear volume of samples for the I-Light and CeramX materials after friction at a load of 10 and $20 \mathrm{~N}$.

A few important factors taken into account when calculating and characterizing the size of wear is load and friction distance. The coefficient of wear for the friction pair using the (1) equation was calculated using a comparative measure of wear, which takes into account both the load and the friction distance. One can compare only the results obtained for the same loads and friction distances. The coefficient of wear for the ILight and CeramX materials at a load of 10 and $20 \mathrm{~N}$ was shown in Figure 3. When analyzing the coefficient of wear at a load of $10 \mathrm{~N}$, one can establish a lower value for the Ceram X material $1.37 \times 10^{-5} \mathrm{~mm}^{3} \mathrm{~N}^{-1} \mathrm{~m}^{-1}$, compared to the I-Light material $1.67 \times 10^{-5} \mathrm{~mm}^{3} \mathrm{~N}^{-1} \mathrm{~m}^{-1}$. When analyzing the coefficient of wear at a load of $20 \mathrm{~N}$, one can also establish a lower value for the CeramX material $0.86 \times 10^{-5} \mathrm{~mm}^{3} \mathrm{~N}^{-1} \mathrm{~m}^{-1}$, compared to the I-Light material $1.37 \times 10^{-5} \mathrm{~mm}^{3} \mathrm{~N}^{-1} \mathrm{~m}^{-1}$.

After testing at a load of $10 \mathrm{~N}$, the average coefficient of friction for the I-Light material was 0.16 and the maximum was 0.62 . The average coefficient of friction for the CeramX material was 0.17 , while the maximum was 0.66 . After testing at a load of $20 \mathrm{~N}$, the average coefficient of friction for the I-Light material was 0.11 and the maximum was 0.51 . The average coefficient of friction for the CeramX material was 0.09 , while the maximum was 0.48 . When analyzing the obtained results, one can establish similar values for both materials tested with a load of $10 \mathrm{~N}$ and $20 \mathrm{~N}$. Figure 4 shows the variation in average and maximum coefficient of friction for the I-Light and CeramX materials.

Several changes in the coefficient of friction were recorded in the course of the tribological tests. Figure 5a and $\mathrm{b}$ shows their change with the load of $10 \mathrm{~N}$ and $20 \mathrm{~N}$ recorded on the distance of $1000 \mathrm{~m}$.

The recorded values of the coefficient of friction for the I-Light and CeramX materials are similar at a load of $10 \mathrm{~N}$ (Fig. 5a) and at 20 $\mathrm{N}$ (Fig. 5b). The values of the coefficient of friction have a stabilized character during friction in the presence of lubricant, which is artificial saliva. The graphs contain a surge point in the coefficient of friction. This occurs when the lubricant layer in the form of an artificial saliva is interrupted. The presence of artificial saliva as lubricant is essential for the correct operation of the friction pair.

The next stage involved tests on the surface after friction. The $\mathrm{R}_{\mathrm{a}}$ parameter was lower for the CeramX material before friction and

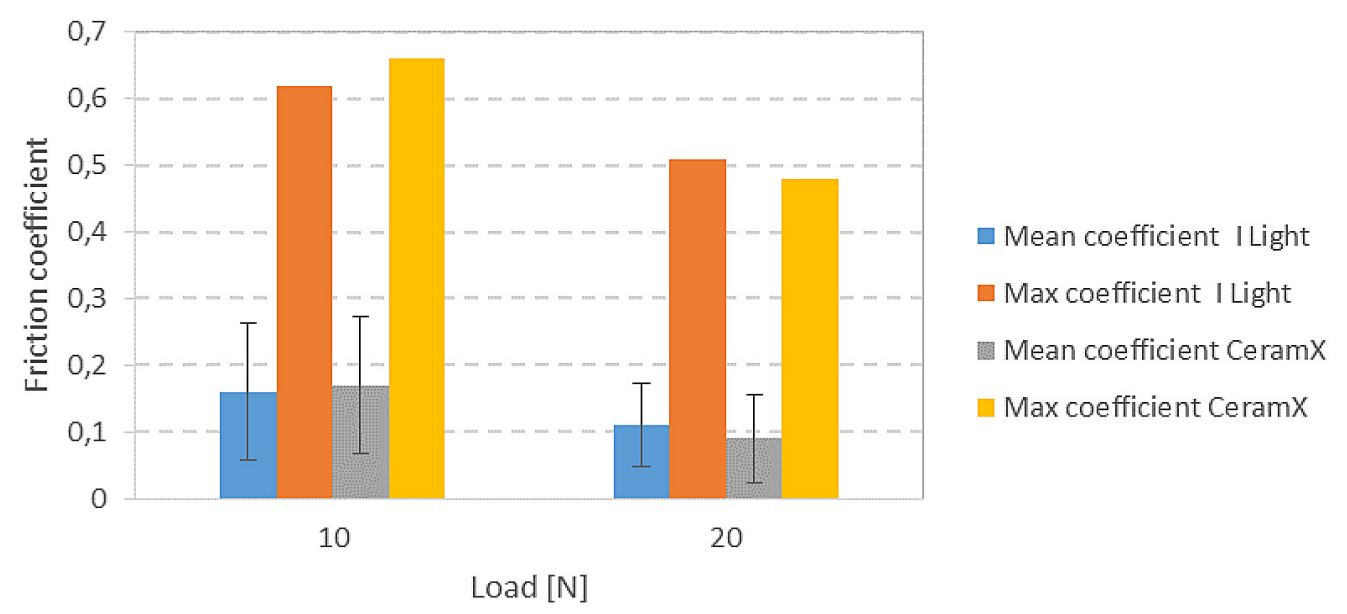

Fig. 4. The coefficient of friction for the I-Light and CeramX materials 
a)

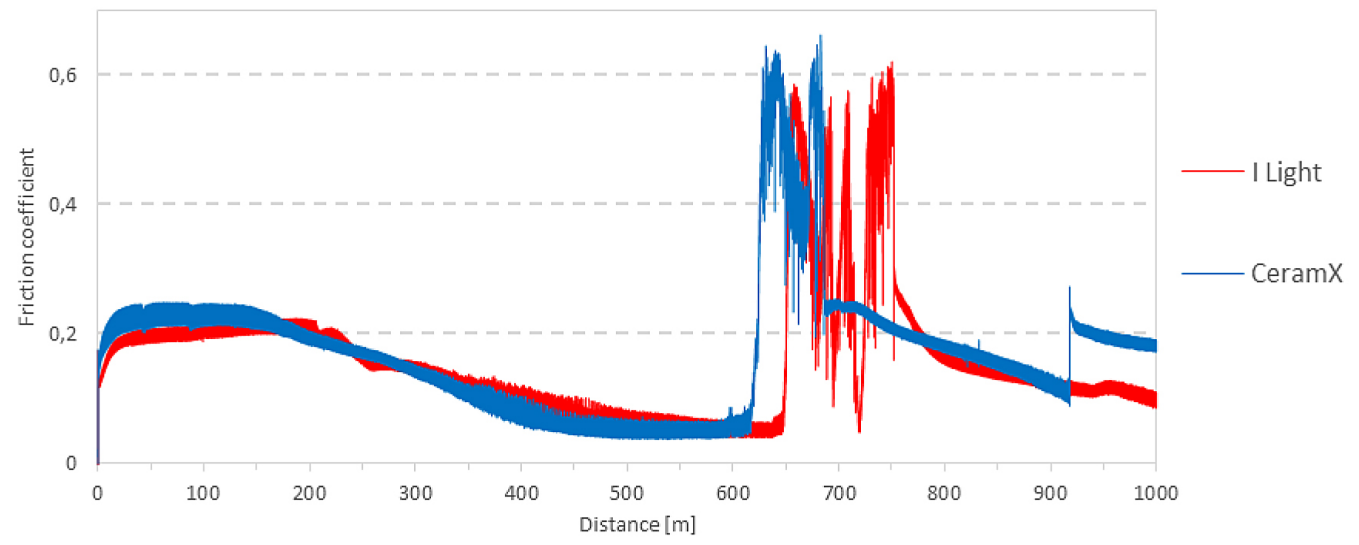

b)

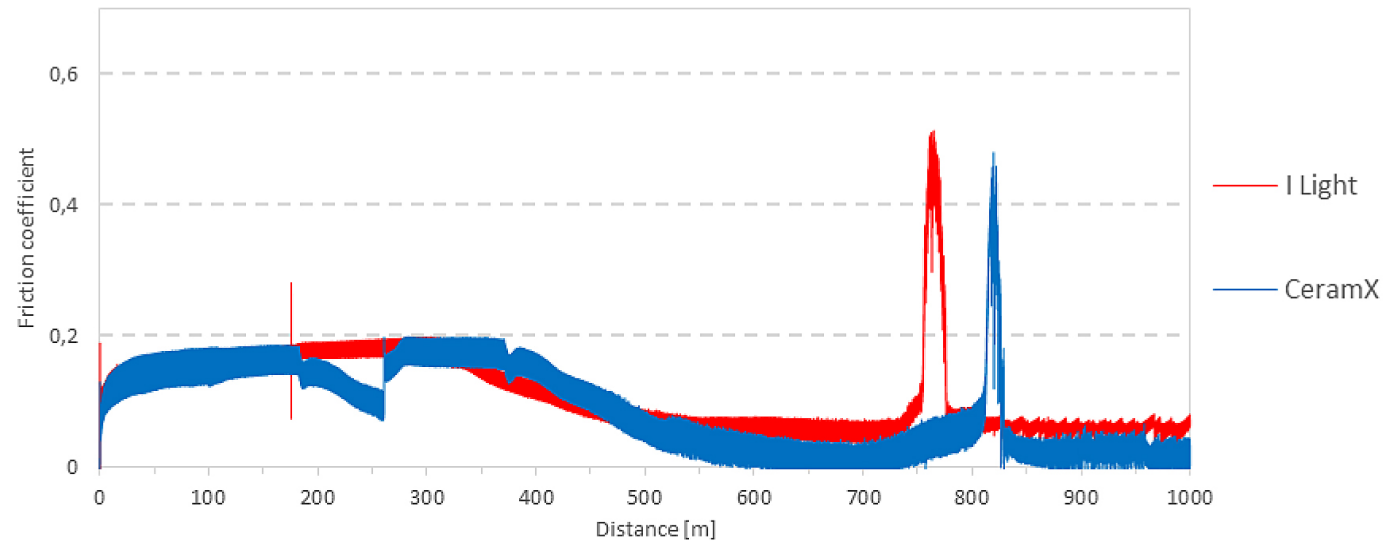

Fig. 5. The course of the coefficient of friction: at a load of: a) $10 \mathrm{~N}$, b) $20 \mathrm{~N}$

a)

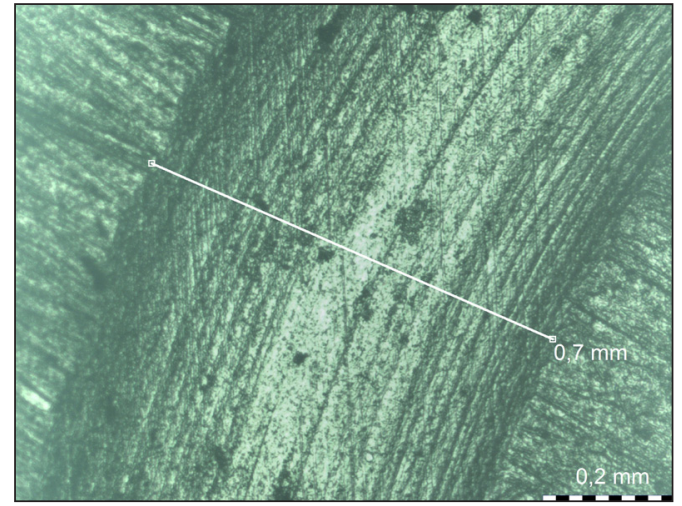

b)

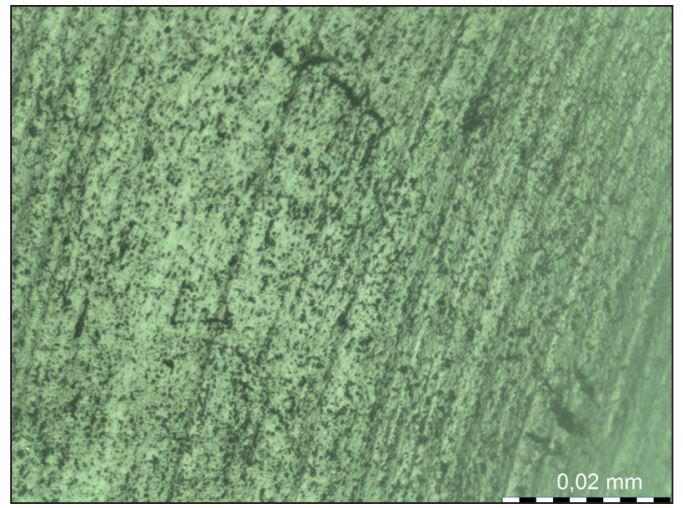

c)

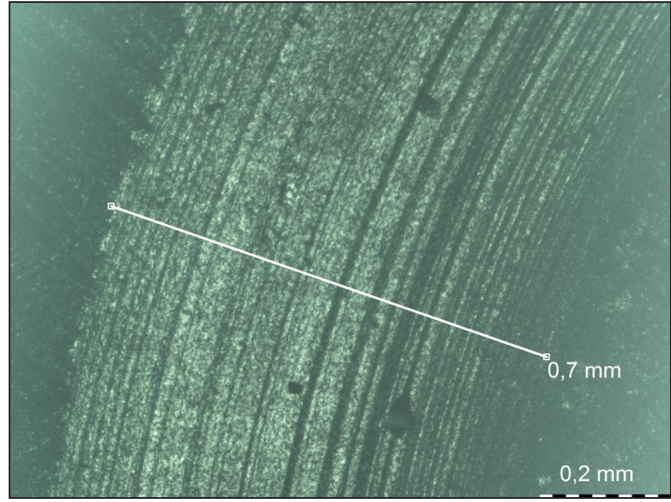

d)

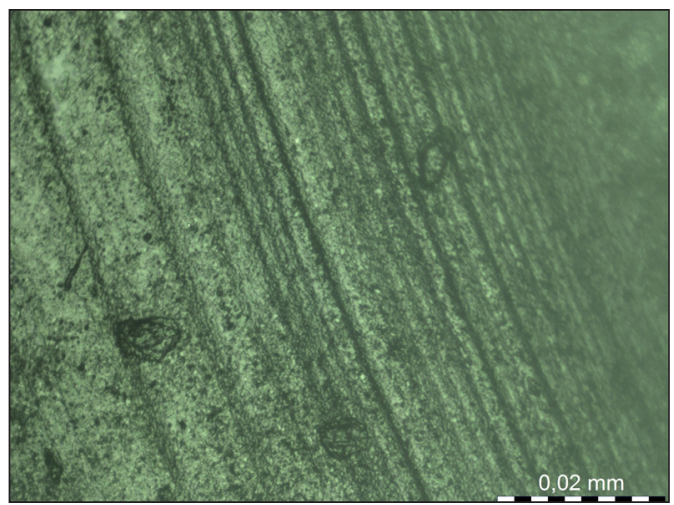

Fig. 6. The view of samples after friction: a) I-Light, area $\times 40$, b) CeramX, area $\times 40$, c) I-Light, area $\times 100, d$ ) CeramX, area $\times 100$ 
amounted to $\mathrm{R}_{\mathrm{a}}=0.57 \mu \mathrm{m}$, and $\mathrm{R}_{\mathrm{a}}=0.68 \mu \mathrm{m}$ for the I-Light material. In order to identify the occurring phenomena and the mechanism of wear, the friction surfaces were subjected to microscopic observations. Figure 6 shows a view of the surface after friction for the I-Light and CeramX materials. The measured width of the friction track for both materials was 0.7 $\mathrm{mm}$ (Fig. 6a and b). The surface of friction contained cracks and grooves demonstrating micromachining (Fig. 6c and d).

\section{CONCLUSION}

This study includes research on the tribological properties and the condition of surfaces of the I-Light and CeramX light-curing dental composite materials. The following values were received:

1. Microhardness of samples amounted to 80.97 $\mathrm{HV}$ for the CeramX material, and $68.43 \mathrm{HV}$ for the I-Light material. The measured average Young's modulus of samples was 14.73 $\mathrm{GPa}$ for the CeramX material, and $14.69 \mathrm{GPa}$ for the I-Light material.

2. There were no signs of wear for the I-Light and CeramX materials at a load of $2 \mathrm{~N}$. The average wear volume for the samples at a load of $10 \mathrm{~N}$ amounted to $0.167 \mathrm{~mm}^{3}$ for the I-Light material, and $0.136 \mathrm{~mm}^{3}$ for the CeramX material. The average wear volume for the ILight material amounted to $0.26 \mathrm{~mm}^{3}$ at a load of $20 \mathrm{~N}$, and $0.17 \mathrm{~mm}^{3}$ for the CeramX material. One can observe better wear properties of the CeramX material compared to the I-Light material at both loads.

3. The coefficient of friction was similar during tests of the CeramX and I-Light materials. At the load of $10 \mathrm{~N}$, the average coefficient of friction for the I-Light material amounted to 0.16 , and 0.17 for the CeramX material. At the load of $20 \mathrm{~N}$, the average coefficient of friction for the I-Light material amounted to 0.11 , and 0.09 for the CeramX material. There were momentary abrupt changes in the coefficient of friction which demonstrate an interruption in lubricating layer in the form of artificial saliva.

4. When analyzing the surfaces of wear, one can observe traces demonstrating the processes of micromachining.
5. The results of this study can form a basis for the development of modern dental composite materials, which will be characterized by good mechanical and tribological properties.

\section{REFERENCES}

1. Mystkowska J., Dąbrowski J.R., Tribological characteristics of the kinematics couple: tooth - composite material for permanent dental fillings, Maintenance and reliability, $\mathrm{Nr}$ 3, 2010, 4-9.

2. Klaczewska J., Bieliński D.M., Friction and wear of resin-based dental materials, Archives of civil and mechanical engineering, Vol. 7, 2007, 87-96.

3. Ozwoniarek J., Wiśniewska-Weinert H., Leshchynsky V., Kędzia Ł. and Gierzyńska-Dolna M. Nowe rozwiązania w zakresie biotribologii i biomateriałów. Obróbka Plastyczna Metali, 17(3), 2006, 29-36.

4. Szafran M., Bobryk E., Szczęsna B. and Jałbrzykowski M. Wpływ dodatku nanowypełniacza na właściwości mechaniczne i tribologiczne kompozytów ceramiczno-polimerowych do zastosowań stomatologicznych. Kompozyty (Composites), 6, 2006, 83-87.

5. Walczak M. Wpływ wybranych zabiegów technologicznych na trwałość użytkową układów metalceramika stosowanych $\mathrm{w}$ protetyce stomatologicznej. Wydawnictwo Politechniki Lubelskiej, Lublin, 2014.

6. Jodkowska E. Materiały kompozycyjne: budowa, klasyfikacja i niektóre właściwości fizyko-chemiczne. Mag. Stom, 1, 1991, 4-7.

7. Grądzka-Dahlke M., Tokajuk G., Wilczko M., Pawińska M. and Stokowska W. Właściwości mechaniczne wybranych kompozytów stomatologicznych stosowanych do stabilizacji zębów, Kompozyty (Composites), 4, 2004, 326-330.

8. Andrzejczuk M., Lewandowska M. and Kurzydłowski K.J. Właściwości mechaniczne światłoutwardzalnych kompozytów zbrojonych mikro- i nanocząstkami. Kompozyty (Composites), 5, 2005, 75-79.

9. Hahnel S., Schultz S., Trempler C., Ach B., Handel G., Rosentritt M., Two-body wear of dental restorative materials, Journal of the mechanical behavior of biomedical materials, Vol. 4, 2011, 237-244.

10. Sajewicz E., Kulesza Z., A new tribometer for friction and wear studies of dental materials and hard tooth tissues, Tribology International, Vol. 40, 2007, 885-895.

11. Sajewicz E., On evaluation of wear resistance of tooth enamel and dental materials, Wear, Vol. 260, 2006, 1256-1261. 